\title{
Fostering Moral Competence With the Konstanz Method of Dilemma Discussion
}

\author{
Kamila Št’astná \\ Roudnice nad Labem, Czech Republic
}

\begin{abstract}
This paper deals with a special program for moral education, specifically using KMDD (the Konstanz method of dilemma discussion). This program is a method that is based on an open moral dilemma discussion in the classroom and has the key intent to cultivate moral competence. According to theory and some research, KMDD has a significant influence on moral competence (Lind, 2012; Nowak, Schrader, \& Zizek, 2013). Moral competence means "the ability to cope with problems, and solve conflicts, on the basis of universal moral ideals through thinking and discussion rather than violence, deceit and power" (Lind, 2011). The purpose of this paper is to present the results of the study undertaken to examine this program. During an academic year in school, this method was implemented in ethics classes for Czech teenagers $(N=42)$. Moral competence was investigated by MCT (Moral Competence Test) in a research group and two control groups before and after the process. However, the results show that there was no significant impact on moral competence KMDD seems to foster different aspects of morality.
\end{abstract}

Keywords: KMDD (Konstanz method of dilemma discussion), MCT (Moral Competence Test), moral behavior, moral competence

\section{Introduction}

Theodore Roosevelt supposedly said, "To educate a man in mind and not in morals is to educate a menace to society". Every school would like to have an effective program for developing moral behavior. There are hundreds of programs and conceptions. Owing to such many programs, it is not easy to decide which one is suitable and which one will have a real positive effect ${ }^{1}$. In this paper, I present the results of my research concerning one of these programs, namely KMDD (the Konstanz method of dilemma discussion). The primary aim of KMDD is developing moral competence, which means "The ability to cope with problems, and solve conflicts, on the basis of universal moral ideals through thinking and discussion rather than violence, deceit and power" (Lind, 2011). KMDD was implemented in ethics classes for an academic year in school by Czech teenagers. Influence of KMDD was investigated by MCT (Moral Competence Test).

\section{KMDD (Konstanz Method of Dilemma Discussion)}

KMDD was developed in the 1970s by moral psychologist Georg Lind. This concept is based on the

\footnotetext{
Kamila Št’astná, Ph.D., high-school (Gymnasium) teacher in Germany, teacher of ethics, religion and history.

1 Marvin Berkowitz and Melinda C. Bier investigated more than 50 different programs concerning moral development. They found that all effective programs used these strategies: professional development, peer interaction, direct teaching, skill training, making the agenda explicit, family and/or community involvement, providing models and mentors, and integration into the academic curriculum (Berkowitz \& Bier, 2005).
} 
philosophy of Habermas's discourse ethics ${ }^{2}$, Piaget's dual-aspect of moral behavior ${ }^{3}$ and proceedings from Kohlberg's just community approach ${ }^{4}$. While the main goal of KMDD is to increase moral competence, the other objectives include developing open communication, argumentation, respect, tolerance, empathy, pro-social behavior, critical thinking, ability to learn and make decisions, and regulating negative effects. According to Georg Lind, moral competence is an ability that can be learnt by doing, namely by thinking, discussing and solving moral problems. He is convinced that the best way to do this is by letting students think, discuss and solve moral problems directly in the class. A teacher use as an instrument a moral dilemma story. The topic of the story should be appropriately attractive, and close to the student's life and experience. The main protagonist of the story should be under time pressure, and should make a difficult moral decision as well as act in accordance with this decision. Each student gets the story in a paper form and has a little time to think about it. After sometime, the students have to decide on the behavior of the story's main protagonist: Was it good or was it bad? They write down arguments to support their respective views. The class is then divided into two groups according to the statements, with one group consisting of those who agree with the protagonist's behavior and the second one of those who do not. Everybody gets time to speak about arguments in the small group. After this, there is a discussion in a plenum that has two rules. The first one is concerned about the climate in the class. The students cannot make any positive or negative comments about their classmates. The second one is called the ping-pong rule and is concerned with a method of discussion. The speaker calls one person who has raised a hand from the other group and allow her to speak. At the end of debate, everybody can change positions, positively assess the arguments of other classmates, assess the discussion, and speak about similar experiences from their own lives.

\section{MCT (Moral Competence Test)}

The Moral Competence Test (MCT) is a method for measuring moral competence that was developed by Georg Lind in the 1970s. The aim of MCT is to find how people measure up to thinking about, discussing and coping with problems through discussion rather than violence. This method has a pen-and-paper-based form and takes10-30 minutes. MCT consists of two moral stories concerning difficult moral tasks and a set of 12 arguments for each story. The arguments are divided into two groups according to polarity. The first group represents pro argumentation and the other group represents contrary argumentation (i.e., six pro statements and six contrary ones). A respondent is asked to rank each argument on a scale from -4 ("Completely disagree") to +4 ("Completely agree"). MCT is based on a combination of two principles - ability for discussion and moral orientation. Ability for discussion means that someone is able regardless of own opinion to think about the arguments put up by others, to distinguish between them and take them into account. Moral orientation means six moral stages, according to Kohlberg. Lind supposes that moral competence is interconnected with Kohlberg's theory of moral development ${ }^{5}$. The highest moral competence is achieved by someone who applies

\footnotetext{
${ }^{2}$ Habermas's Discourse Ethics is based on achieving mutual understanding through argumentation. According to him, it requires an ideal speech situation in which some of the key principles are reciprocity and symmetry. It means that the participants have equal rules and conditions to speak, to listen, and to influence argumentation.

3 Piaget reasoned that the two aspects of moral behavior - affective and cognitive-were inseparable and irreducible. Affective aspect refers to moral orientation (values) and cognitive aspect concerns moral competence.

${ }^{4}$ The just community approach is a moral education program developed by Lawrence Kohlberg, Moshe Blatt, and their colleagues. The goal is to promote democratic decision-making and foster moral judgment through dilemma discussion.

5 Stage 1: Punishment-Obedience Orientation, Stage 2: Instrumental Relativist Orientation, Stage 3: Good Boy-Nice Girl Orientation, Stage 4: Law and Order Orientation, Stage 5: Social Contract Orientation, and Stage 6: Universal Ethical Principle Orientation.
} 
these two principles in the MCT. It practically means to mark +4 for those statements that correlate to the highest stage of moral orientation and mark those statements less that correlate to the lowest stage of moral orientation regardless polarity of arguments. The default value is $\mathrm{C}$-score which means moral competence. C-score can have values that are low (0-10), medium (10-30), high (30-40), and very high (50 and more). MCT is not intended for an individual investigation but for the investigation of a group, with a minimum of 13 members. The reason for this is because possible circumstances such as stress, bad mood and other individual problems can influence individual scoring (Lind, 2012).

\section{Goal of the Research}

To measure the impact of KMDD on moral competence.

\section{Primary Hypothesis}

Hypothesis 1: KMDD has a significant impact on increasing moral competence.

\section{Secondary Hypotheses}

Hypothesis 2a: All groups show significant increase in their moral competence after the process.

Hypothesis $2 \mathrm{~b}$ : The research group shows significantly more increase in moral competence than the two control groups.

Hypothesis 2c: The two control groups show equal increase in their moral competence.

\section{Method}

\section{Sample}

The sample comprises 42 students. All the students are Czech citizens, attend gymnasium in Germany, are highly intelligent, come mostly from families with good economic background, and all of them live in a boarding house. The students are divided into three groups-one research group and two control groups - according to age and year of study. KMDD was applied on all these groups; seven times on the research group and three times on the control groups.

Table 1

Sample

\begin{tabular}{llllll}
\hline Group & $N$ & Female & Male & Age & Year of study \\
\hline Research group (A) & 15 & 7 & 8 & $12-13$ & 1 \\
1. Control group (B) & 13 & 7 & 6 & $14-15$ & 3 \\
2. Control group (C) & 14 & 6 & 8 & $15-16$ & 4 \\
\hline
\end{tabular}

Table 2

Methods

\begin{tabular}{|l|l|}
\hline MCT & Pretest, Posttest \\
\hline $\begin{array}{l}\text { Nonparametric statistical methods } \\
\text { STATISTICA 12) }\end{array}$ & $\begin{array}{l}\text { Kruskal-Wallis-Test: Verify the statistical significance between } \\
\text { more than two non-independent groups. }\end{array}$ \\
\cline { 2 - 2 } $\begin{array}{l}\text { Wilcoxon Signed-Rank Test: Verify the statistical significance } \\
\text { between C-score pretest and posttest in one group. }\end{array}$ \\
\hline Binomial effect size display (BESD) & $\begin{array}{l}\text { Verify the C-score difference between pretest and posttest in } \\
\text { one group in percent value (Lind, 2007). }\end{array}$ \\
\hline
\end{tabular}

\footnotetext{
${ }^{6}$ I chose them because the sample was relatively small and for non-normal distribution.
} 


\section{Procedure}

The process started in December 2012 and lasted till July 2013. In December, all students completed the MCT (pretest) over a duration of 10-30 minutes. The research group was subjected to two KMDD sessions in January and one each in February, March, April, May and June. The control groups faced three monthly KMDD sessions in January, February and March. The KMDD session always took 1.5 hours. In July, all the students completed MCT (posttest).

Table 3

Variables

\begin{tabular}{|l|l|}
\hline \multirow{2}{*}{ Independent variable } & KMDD (seven sessions) in the research group \\
\cline { 2 - 2 } & KMDD (three sessions) in the control groups \\
\hline Dependent variable & Moral competence \\
\hline Intervening variable & Education formation \\
\hline
\end{tabular}

\section{Intervening Variable: Education Formation}

Education has strong impact on moral competence, according to Lind's theory and another research. Lind argues that education has an average of $3.5 \%$ per a year influence on moral competence (Lind, 2002, 2007; Nowak et al., 2013). This finding was necessary to take into account in the context of this research. The influence of education was tested among all the groups. Each group is in a different year of study. The research group (R) is in first year, the control group (C1) in third year and the second control group (C2) in fourth year. To see the impact of education more clearly, one more group, namely the second year class $(\mathrm{X})$ from the same school, was added as well. This class was added only for the determination of the intervening variable. I did not work with it any further?

All the groups took the MCT (pretest) and the results of the MCT were compared by using the statistical methods of Kruskal-Wallis-Test and BESD.

Table 4

Results of $M C T$

\begin{tabular}{ll}
\hline Group (year of study) & C-score \\
\hline R (1) & 21.9 \\
X (2) & 23.6 \\
C1 (3) & 23.9 \\
C2 (4) & 28.1 \\
\hline
\end{tabular}

It is evident from the values in the table that there is a gradual increase of $\mathrm{C}$-score in relation to the year of study. The increase is of roughly $2 \%$, except in the case of group $\mathrm{C} 1$.

The results of the analysis by the Kruskal-Wallis-Test are $H(3, N=57)=036 ; p=0.9483$. It indicates that this increase is not statistically significant.

The values in the table show that there is a little increase in the C-score due to education. This data will be taken into account in the final results. For the research group, the value of 1.7 will be subtracted after the process because it could be due to education but not due to the influence of KMDD. The value 4.2 will be subtracted in the control group (C1) and the value 2 (as a mean) will be subtracted in the control group (C2).

\footnotetext{
${ }^{7}$ I could not include this class in my sample because of a specific schedule that they had. However, I did another research with this class, also concerning moral competence (Stastna, 2014).
} 
Table 5

Results of BESD

\begin{tabular}{lll}
\hline Comparing groups & C-score & aES (percent (\%)) \\
\hline X-R & $23.6-21.9$ & 1.7 \\
C1-X & $23.9-23.6$ & 0.3 \\
C2-C1 & $28.1-23.9$ & 4.2 \\
\hline
\end{tabular}

\section{Results}

\section{Research Group (R)}

Table 6

Results of MCT Pretest and Posttest (R)

\begin{tabular}{lccccccccccccccc}
\hline Student & 1 & 2 & 3 & 4 & 5 & 6 & 7 & 8 & 9 & 10 & 11 & 12 & 13 & 14 & 15 \\
\hline Pretest & 5.01 & 6.8 & 7.71 & 13.46 & 14.73 & 17.69 & 17.76 & 20.44 & 21.07 & 26.61 & 32.19 & 34.17 & 34.41 & 35.44 & 41.45 \\
Posttest & 13.78 & 14.15 & 13.25 & 37.6 & 14.09 & 10.54 & 32.72 & 31.42 & 19.63 & 23.79 & 54.57 & 19.03 & 51.86 & 33.13 & 2.12 \\
\hline
\end{tabular}

Note. Mean of pretest: 21.9; Mean of posttest: 24.8 .

I analyzed the figures by the Wilcoxon Signed-Rank Test.

Table 7

Wilcoxon Signed-Rank Test (R)

\begin{tabular}{lllll}
\hline Couple variable & $N$ & $T$ & $Z$ & $p$ \\
\hline C-score pretest and posttest & 15 & 42 & 1.022331 & 0.306625 \\
\hline
\end{tabular}

The Wilcoxon signed-rank test shows that there is no statistical importance between the C-score pretest and posttest.

BESD comes up with the following data: The mean of the pretest is equal to 21.9 and the mean of the posttest is equal to 24.8 . The resulting value is $24.8 \%-21.9 \%=2.9 \%$. It means that there was a marginal increase of the $\mathrm{C}$-score. By necessarily subtracting the influence of intervening variables, the value is equal to $1.7 \%$. The value of KMDD is effectively $(2.9 \%-1.7 \%)=1.2 \%$.

\section{Control Group (C1)}

The same method used for the research group was applied for the other two groups as well. First, MCT (pretest and posttest), then Wilcoxon Signed- Rank Test and lastly BESD.

Table 8

Results of MCT Pretest and Posttest (C1)

\begin{tabular}{lrlrllllllllll}
\hline Student & 1 & 2 & \multicolumn{1}{c}{3} & 4 & 5 & 6 & 7 & 8 & 9 & 10 & 11 & 12 & 13 \\
\hline Pretest & 4.33 & 4.38 & 9.38 & 11.73 & 14.76 & 20.88 & 22.22 & 27.68 & 29.97 & 34.77 & 42.01 & 42.43 & 46.43 \\
Posttest & 12.74 & 4.33 & 16.35 & 57.54 & 26.58 & 31.57 & 25.48 & 43.6 & 14.25 & 23.77 & 42.32 & 31 & 28.59 \\
\hline
\end{tabular}

Note. Mean of pretest: 23.9; Mean of posttest: 27.5.

Table 9

Wilcoxon Signed-Rank Test (C1)

\begin{tabular}{lllll}
\hline Variable & $N$ & $T$ & $Z$ & $p$ \\
\hline C-score pretest and posttest & 13 & 38 & 0.524142 & 0.600180 \\
\hline
\end{tabular}


The Wilcoxon Signed-Rank Test shows that there is non-statistical importance between the C-score pretest and posttest. BESD shows a value of 3.29\% (27.5\% - 23.9\%). By necessarily subtracting the influence of intervening variables, the value is equal to $4.2 \%$. The value of KMDD is effectively $-0.6 \%$. It means that there was no effect.

\section{Control Group (C2)}

Table 10

Results of MCT Pretest and Posttest (C2)

\begin{tabular}{lllllllllllllll}
\hline Student & 1 & 2 & 3 & 4 & 5 & 6 & 7 & 8 & 9 & 10 & 11 & 12 & 13 & 14 \\
\hline Pretest & 11.13 & 15.06 & 25.94 & 25.24 & 21.15 & 29.34 & 32.65 & 30.33 & 28.64 & 3.69 & 22 & 68.77 & 66.5 & 13.23 \\
Posttest & 21.77 & 11.17 & 40.63 & 17.75 & 19.94 & 16.19 & 28.39 & 20.54 & 27.14 & 17.05 & 36 & 62.14 & 69.24 & 42.2 \\
\hline
\end{tabular}

Note. Mean of pretest: 28.1; Mean of posttest: 30.7 .

Table 11

Wilcoxon Signed-Rank Test (C2)

\begin{tabular}{lllll}
\hline Variable & $N$ & $T$ & $Z$ & $p$ \\
\hline C-score pretest and posttest & 14 & 43 & 0.596377 & 0.550924 \\
\hline
\end{tabular}

According to the Wilcoxon Signed-Rank Test, there is no statistical importance of the KMDD impact. BESD shows a value of $2.62 \%(30.7 \%-28.1 \%)$. By necessarily subtracting the influence of intervening variables, the value is equal to $2 \%$. The value of KMDD is effectively $0.6 \%$.

In this graph, we may see the influence of KMDD regarding the intervening variable.

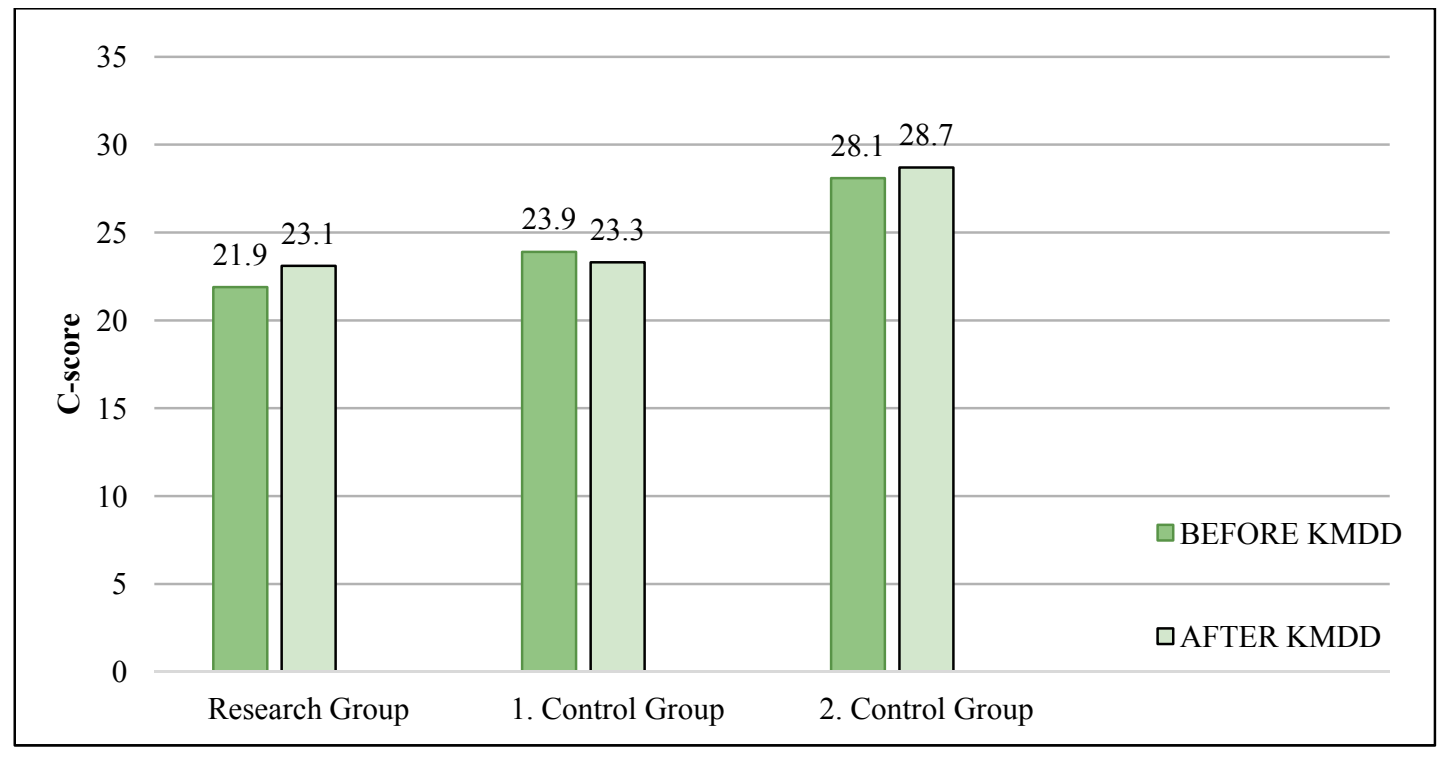

Figure 1. Influence of KMDD.

\section{Interpretation of Results and Discussion}

The hypotheses were not confirmed and the results revealed that KMDD did not have significant impact on moral competence. All the groups did not show significant increase in their moral competence after the process. Nevertheless, the research group increased moral competence slight as compared to the two control groups. 
The question is why KMDD did not have any strong impact on moral competence. I have listed the results of other research and I found four published studies that examined more or less same issue as I did. The first one is from Georg Lind. He conducted a longitudinal study $(N=3,102)$, carried out in Germany between 2002 and 2009. The participants were from one German university, and were enrolled in psychology or teacher education programs. By using KMDD over one semester, Lind reported an increase in moral competence between $7.9 \%$ and $15.7 \%$ (Lind, 2014). The next research comes from Sanguan Lerkiatbundit, a professor from Prince of Songkla University in Thailand. His investigation subjects $(N=83)$ included pharmacy technicians and dental nursing students. The experimental group participated once a week for six consecutive weeks. He found significant impact (15\%) of KMDD (Lerkiatbundit, 2006). The third study wrote Jing Zhang from Guangdong University of Foreign Studies in China. She investigated undergraduate students majoring in economics in China $(N=89)$. After seven KMDD sessions, she observed just a marginal increase of $0.32 \%$ (Zhang, 2013). Another study by Víctor Hugo Robles Francia, a professor at the University of Guanajuato in Mexico, used seven KMDD sessions with 32 university students. He did record a decline in the C-score, from $17.5 \%$ to $15.4 \%$ (Robles, 2011 ).

However, there are different findings, as I perceived similar limits in these research studies regarding the teacher's personality, ability of students, environment, and MCT.

Georg Lind and Sanguan Lerkiatbundit record significant impact of KMDD. Jing Zhang and my research indicate marginal influence, while Hugo Robles Franca records a decline. I presume that effect of KMDD depends on different factors that are needed to be studied. Some of those components could be teacher's personality, student's IQ, EQ, and other features like number of KMDD sessions, environment, class-schedule etc. Perhaps the marginal effect of 1.2 in the research group in my study indicates that more sessions of KMDD are needed for a significant impact. It could be similar to the case of studying a language. We improve through practice: some people need more time and some less.

Another limit concerns moral competence measurement by MCT. There is an interesting research that verified a connection between MCT and neurobiological factor (Prehn, 2013). Another research confirmed correlation between learning environment and moral competence (Schillinger, 2013). Despite that fact, MCT is only one method to measure moral competence. Even if I did not measure significant impact I noticed, that KMDD motivated students and engage their will, mind and emotion. They learned to be were aware of own opinion, arguments, feelings and to show them in adequate way. In addition they learned to reflect and evaluate arguments of classmates. They often continued with argumentation after the class. They perceived that morality is not something what is far away, by contrast that it is real, here and concerns all of us. They realized, that many conflicts arise due to misunderstanding, low will, low respect or low empathy. It was evident, that they felt the strong power of intuition on a moral judgement (Haidt, 2012). I presume, the students developed due to KMDD different domains of morality. It will be interesting to do a study regarding moral sensitivity, moral action or moral motivation (as per the categorization by Narváez and Endicott, 2009) and to measure influence of KMDD on these domains.

\section{Conclusion}

The purpose of this research was to apply KMDD and to measure the impact on moral competence. I carried out seven sessions of KMDD in research group and three sessions in control groups. KMDD was for the students an effective motivation itself. Their focus and engagement was tremendously high. They were 
positively tuned, they listened attentively to each other and they exchanged arguments and assessed them. I measured the impact on the moral competence by MCT before and after the process. MCT did not indicate any significant effect. I suppose it could be due to the low number of KMDD sessions, the teacher's personality, due to ability of students, environment, and MCT. Nevertheless, moral competence is an ability and probably it requires more time to be fostered, the same as to do exercise and to improve in the sport or languages. The true effect of KMDD and the impact on moral competence and on other factors of moral behavior can be an interesting issues for further investigations.

\section{References}

Berkowitz, M. W., \& Bier, M. C. (2005). What works in character education: A research-driven guide for educators. Washington, DC: Character Education Partnership. Retrieved from http://www.rucharacter.org/file/practitioners_518.pdf

Blatt, M., \& Kohlberg, L. (1975). The effect of classroom moral discussion upon children's level of moral judgment. Journal of Moral Education, 4, 129-161.

Haidt, J. (2012). The righteous mind: Why good people are divided by politics and religion. New York: Pantheon.

Kohlberg, L. (1985). Just community approach to moral education. In Berkowitz, Marvin W a Fritz Oser (Eds.), Moral education: Theory and application. Hillsdale, N. J.: L. Erlbaum Associates.

Lerkiatbundit, S. (2006). Randomized controlled study of the impact of the Konstanz method of dilemma discussion on moral judgement. Journal of Allied Health, 35(2), 101-108.

Lind, G. (2011). Editorial: Moral competence and the democratic way of living. Europe's Journal of Psychology, 7(5), $569-596$.

Lind, G. (2014). Effektstärken: Statistische, praktische und theoretische Bedeutsamkeit empirischer Studien. Konstanz. Retrieved from http://www.uni-konstanz.de/ag-moral/pdf/Lind-2009_Favorable_learning.pdf

Lind, G. (2002). Ist Moral lehrbar? Ergebnisse der modernen moralpsychologischen Forschung. 2. Auf. Berlin: Logos-Verl.

Lind, G. (2007). The relative and absolute effect size of the Konstanz method of dilemma discussion (KMDD). http://www.uni-konstanz.de/ag-moral/pdf/Lind-2007_effect-size-KMDD.pdf

Narváez, D., \& Endicott, L. G. (2009). Ethical sensitivity. Notre Dame, I.N.: Alliance for Catholic Education Press.

Nowak, E., Schrader, D., \& Zizek, B. (2013). Educating competencies for democracy. New York: Peter Lang Verlag, 2013. ISBN 36-316-2472-7.

Prehn, K. (2013). Moral judgment competence: A re-evaluation of the dual-aspect theory based on recent neuroscientific research. In E. Nowak, D. Schrader, \& B. Zizek (Eds.), Educating competencies for democracy (pp. 9-22). Frankfurt am Main: Peter Lang Verlag.

Schillinger, M. (2013). Verifying the dual-aspect theory: A cross-cultural study on learning environment and moral judgment competence. In E. Nowak, D. Schrader, \& B. Zizek (Eds.), Educating competencies for democracy (pp. 9-22). Frankfurt am Main: Peter Lang Verlag.

Robles, F. V. H. (2011). La ineficacia de la discusión de dilemas morales en el crecimiento de la competencia moral en trabajadores y estudiantes. Dos casos Mexicanos. (The ineffectiveness of moral dilemma discussion in the growth of moral competence in workers and students). Revista CES Psicología, 4(2), 47-59.

Št’astná, K. (2014). Problematika výuky morální výchovy na českých školách (The issue of moral education in Czech schools)( PhD dissertation, Charles University).

Zhang, J. (2013). Cultivating moral competence of chinese undergraduates with KMDD-sessions. Ethics in Progress, 4(1), 48-56. 